\title{
Prevalence of Anemia and Renal Insufficiency in Non-Hospitalized Patients with Heart Failure
}

\author{
Francisco José Farias Borges dos Reis, André Maurício Souza Fernandes, Almir Galvão Vieira Bitencourt, \\ Flávia Branco Cerqueira Serra Neves, André Yoichi Kuwano, Victor Hugo Pinheiro França, Cristiano Ricardo Bastos \\ de Macedo, Cristiano Gonçalves da Cruz, Viviane Sahade, Roque Aras Júnior. \\ Hospital Universitário Professor Edgar Santos - UFBA, Salvador, BA, Brasil
}

\author{
Summary \\ Background: Heart Failure (HF) is a common disease with a high rate of mortality. Anemia and renal failure (RF) are \\ often found in patients with HF associated with higher severity of the heart disease and a worse prognosis.
}

Objective: To evaluate the prevalence of anemia and RF, as well as the association between these two conditions, in non-hospitalized patients with HF.

Methods: Patients treated at the HF Outpatient Clinic of a university hospital were followed from July 2003 to November 2006. Anemia was defined as hemoglobin levels $<13 \mathrm{mg} / \mathrm{dl}$ for men and $12 \mathrm{mg} / \mathrm{dl}$ for women. Renal function was assessed by the glomerular filtration rate (GFR), calculated by the simplified formula of the MDRD (Modification of Diet in Renal Disease) study.

Results: Of the 345 patients included in this study, 26.4\% $(n=91)$ had anemia and $29.6 \%$ had moderate to severe renal failure (GFR $<60 \mathrm{ml} / \mathrm{min}$ ). The association between anemia and a higher prevalence of renal failure was statistically significant $(41.8 \%$ vs. $25.2 \% ; p=0.005)$. The patients at functional class III and IV presented a higher incidence of anemia $(39.0 \%$ vs. $19.4 \% ; p<0.001)$ and renal failure $(38.2 \%$ vs. $24.8 \% ; p=0.007)$. No association was observed between anemia or renal failure and history of hypertension, diabetes, systolic function or etiology of HF.

Conclusion: The prevalence of anemia and renal failure was high in this population and was associated with the severity of the HF (functional classes III and IV). (Arq Bras Cardiol 2009; 93(3):249-254)

Key Words: Heart failure; anemia; renal insufficiency.

\section{Introduction}

Heart failure (HF) is a frequent clinical condition and is associated with high cost, disability and high mortality ${ }^{1}$. Anemia and renal insufficiency (RI) are frequent comorbidities found in patients with HF and are associated with higher severity of heart disease and worse prognoses ${ }^{2,3}$. About $40 \%$ of patients hospitalized with HF present anemia and up to $50 \%$ have moderateto-severe $\mathrm{RI}^{4}$. These conditions are pathophysiologically interconnected, forming the Cardiorenal Syndrome (CRS), whereby each component (anemia, RI and HF) is capable of causing or overstimulating the other, resulting in a vicious cycle $\mathrm{e}^{4-6}$.

The aim of this study is to describe the prevalence and evaluate the association between anemia and $\mathrm{RI}$ in patients with HF, followed-up in a reference clinic in Salvador, Bahia, Brazil.

Mailing Address: André Maurício Souza Fernandes •

Rua das Acácias, 67 - Pituba - 41850010 - Salvador, BA, Brasil

E-mail: andremsf@hotmail.com, andremsf@cardiol.br

Manuscript received on October 06, 2007; revised manuscript received on

February 29, 2008; accepted on March 28, 2008.

\section{Methodology}

This was a cross-sectional study with patients followed-up at the heart failure clinic of the Professor Edgar Santos University Hospital (HUPES) - Federal University of Bahia (UFBA). This clinic provides reference service for HF patients in the State of Bahia, Brazil, an endemic zone for Chagas disease (CD). Patients admitted at the clinic between July 2003 and November 2006 were included in this study. Inclusion criteria were clinical and echocardiographic diagnosis of HF, with laboratory tests including serum creatinine and hemoglobin $(\mathrm{Hb})$. Patients with kidney failure who had already undergone dialysis treatment at admission and those diagnosed with HF discharged in subsequent evaluations were excluded from the analysis. The investigation conforms to the principles outlined in the Declaration of Helsinki, and all subjects provided informed consent before participation. There are no conflicts of interest in this study, which was submitted to the HUPES Human Research Ethics Committee.

The following clinical and demographic characteristics were analyzed: gender, age, race, previous history of hypertension, diabetes mellitus (DM) and kidney failure, medications used, duration of illness in months, main etiology of the cardiomyopathy, and functional class (FC) 
according to New York Heart Association (NYHA) criteria. $\mathrm{HF}$ was diagnosed by the attending physician, using clinical data and complementary exams brought in at the time of the initial visit. The main etiology of cardiomyopathy was attributed based on the patient's clinical history, physical and complementary examinations. At least two positive serological tests were necessary for the diagnosis of Chagas cardiomyopathy; history of angina; acute myocardial infarction, percutaneous transluminal coronary angioplasty, suggestive electrocardiographic abnormalities, obstructive lesion demonstrated on coronary angiography or ischemic changes on complementary examinations were needed for ischemic cardiomyopathy; previous history of uncontrolled hypertension, therapy with different antihypertensive drugs or presence of targetorgan damage, such as left ventricular hypertrophy on electrocardiogram or echocardiogram, changed ophthalmoscopy or chronic kidney failure was necessary for hypertensive cardiomyopathy. When ischemic and hypertensive etiology were both present, the former was considered as the main one. Others etiologies (valvar, hypertrophic or restrictive cardiomyopathy, alcoholic, peripartum, viral, and endomyocardial fibrosis) were attributed according to individual patient data. Idiopathic cardiomyopathy was considered when all other etiologies were discarded.

Patients with HF symptoms and left ventricular ejection fraction (LVEF) equal to or greater than $45 \%$ on the echocardiogram (Teichholz method) were considered to have HF with normal systolic function (diastolic HF), in accordance with European Society of Cardiology criteria. The echocardiogram should be performed a maximum of 6 months from admission. Anemia was diagnosed when $\mathrm{Hb}$ serum level was lower than $13 \mathrm{mg} / \mathrm{dL}$ for men and $12 \mathrm{mg} /$ $\mathrm{dL}$ for women on any patients' visits to the service. Blood analyses could be requested at any time from admission to the subsequent visits at the HF clinic. Renal function was evaluated through the estimated glomerular filtration rate (GRF) calculated by the Modification of Diet in Renal Disease (MDRD) simplified equation [GRF $\left(\mathrm{ml} / \mathrm{min} / 1.73 \mathrm{~m}^{2}\right)=186 \mathrm{x}$ (Serum Creatinine $)^{-1,154} \times$ year of age $e^{-0,203} \times(0,742$ if woman) $x$ (1.210 if Negro)], as suggested by the National Kidney Foundation. Kidney function was classified into five stages: normal kidney function (GRF $\geq 90 \mathrm{ml} / \mathrm{min}$ ); mild RI (GRF $\geq 60 \mathrm{ml} / \mathrm{min}$ and $<90 \mathrm{ml} / \mathrm{min}$ ); moderate RI (GRF $\geq 30 \mathrm{ml} /$ min to $<60 \mathrm{ml} / \mathrm{min}$ ); severe RI (GRF $\geq 15 \mathrm{ml} / \mathrm{min}$ to $<30 \mathrm{ml}$ / $\mathrm{min})$; and kidney failure (GRF $<15 \mathrm{ml} / \mathrm{min})^{7}$.

Statistical analyses were performed using SPSS for Windows, version 9.0 (SPSS Inc. Chicago, Illinois). Categorical data were presented as percentages. Continuous variables were expressed as mean and standard deviation when distribution was normal or median and 25-75 percentiles when distribution was abnormal. The following tests were used to compare variables: chi-square test when both variables were categorical, and Student's t-test and MannWhitney test when one of the variables was continuous with and without normal distribution, respectively. The $P$ value used was 0.05 .

\section{Results}

From 725 patients consecutively admitted in the clinic during the period, 345 were included in this study. Clinical and demographic characteristics of this population are summarized in Table 1.

Moderate-to-severe RI (GRF $\leq 60 \mathrm{ml} / \mathrm{min}$ ) was found in $29.6 \%(n=102)$ of all patients, while anemia was present in $26.4 \%(n=91)$. Chart 1 presents the stages of RI according to the GFR and Chart 2 shows the frequency of anemia in groups with different stages of RI.

Patients with anemia, in comparison to those without anemia, had higher prevalence of moderate-to-severe RI and

Table 1 - Clinical and demographical characteristics of patients included $(n=345)$.

\begin{tabular}{|c|c|}
\hline Characteristics & Value \\
\hline Male gender - \% (N) & $56.2(194)$ \\
\hline Negro race - \% (N) & $42.6(147)$ \\
\hline Age in years: Mean (Standard Deviation) & $54.4(13,3)$ \\
\hline Duration of heart disease: Median (P25-P75) & $41(20-93)$ \\
\hline Hypertension- \% (N) & $54.2(156)$ \\
\hline Diabetes Mellitus - \% (N) & $9.3(32)$ \\
\hline \multicolumn{2}{|l|}{ Medications used - \% (N) } \\
\hline Angiotensin-Converting Enzyme Inhibitors (ACEI) & $74.3(254)$ \\
\hline Angiotensin II Receptor Blockers (ARB) & $11.4(39)$ \\
\hline Spironolactone & $46.4(159)$ \\
\hline Loop diuretics & $66.7(228)$ \\
\hline Thiazide diuretics & $24.6(84)$ \\
\hline Acetylsalicylic Acid & $16.7(57)$ \\
\hline LVEF in \%: Median (P25-P75) & $36.0(28.0-45.8)$ \\
\hline Preserved Systolic Function (LVEF $\geq 45 \%$ ) - \% & $28.7(99)$ \\
\hline \multicolumn{2}{|l|}{ NYHA Functional Class (FC) - \% (N) } \\
\hline $\mathrm{FCl}$ & $21.2(73)$ \\
\hline $\mathrm{FC} \|$ & $43,2(149)$ \\
\hline FC III & $27,0(93)$ \\
\hline FC IV & $8,7(30)$ \\
\hline \multicolumn{2}{|l|}{ Heart Failure Etiology - \% (N) } \\
\hline Chagasic & $43,9(151)$ \\
\hline Hypertensive & $21,2(73)$ \\
\hline Idiopathic & $11,6(40)$ \\
\hline Ischemic & $9,9(34)$ \\
\hline Others & $13,4(46)$ \\
\hline
\end{tabular}

LVEF - Left Ventricular Ejection Fraction / NYHA - New York Heart Association 
more frequently fell into the FC III or IV categories (Table 2). Comparing the patients with moderate-to-severe RI to those with $\mathrm{GRF} \geq 60 \mathrm{mg} / \mathrm{dL}$, the former were older, tended to be female, had anemia, functional class III and IV and hypertensive etiology (Table 3). There was a lower prevalence of Negroes and idiopathic etiology in the first group (Table 3). Charts 3 and 4 show, respectively, prevalence of anemia and moderate-to-severe RI in patients with different functional classes (NYHA).

\section{Discussion}

The prevalence of anemia in this study was similar to that found in literature among non-hospitalized patients (26.4\%) and was higher in patients with more severe disease (NYHA FC III or IV) and in those with moderate-to-severe RI. In previous studies, prevalence of anemia varied from $4 \%$ to $69.7 \%$, depending on diagnostic criteria and population studied ${ }^{8,9}$. Characteristics of the studied population are important factors as many studies reveal, for example, a higher prevalence in older patients and in those with decompensated heart disease $^{2,8}$. For Silverberg et $a l^{10}$, patients in functional class IV (NYHA) were more affected by anemia, $79.1 \%$ versus $9.1 \%$ in

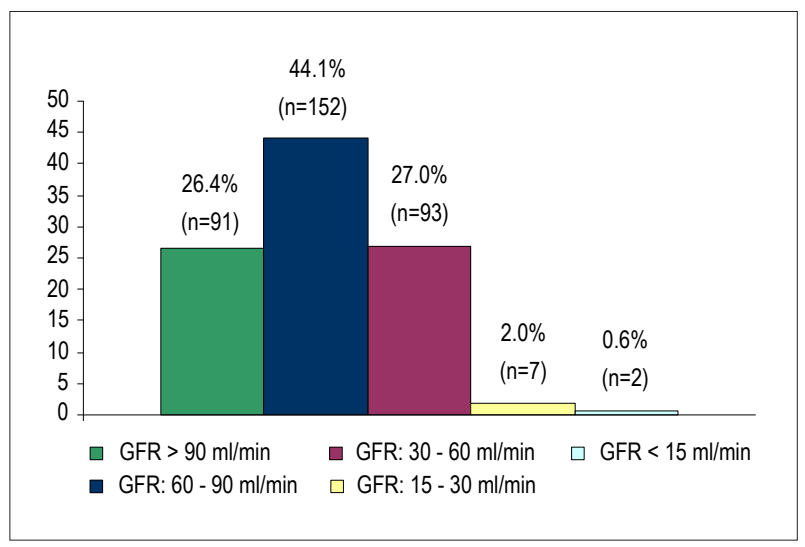

Chart 1 - Classification of renal function according to estimated glomerular filtration rate (GRF) calculated by the simplified Modification of Diet in Renal Disease (MDRD) equation ( $n=345)$.

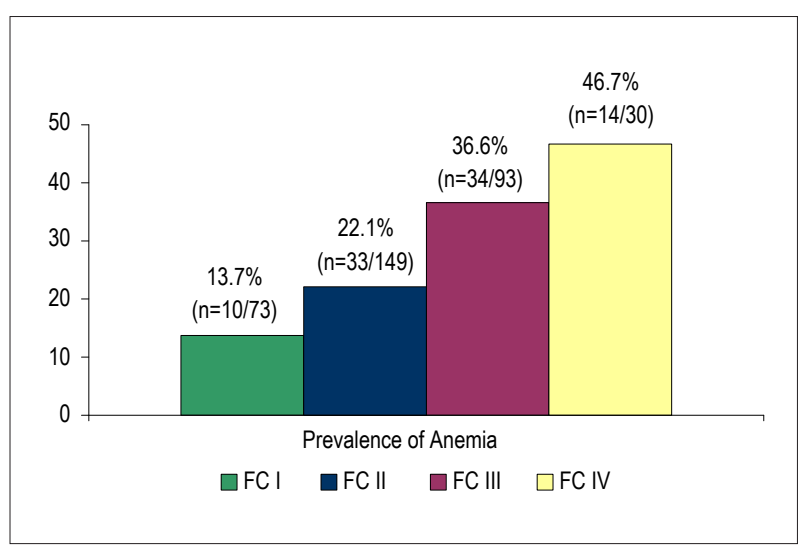

Chart 3 - Prevalence of anemia in different groups of patients grouped according to New York Heart Association (NYHA) functional class (FC). patients with FC I. In non-hospitalized patients this prevalence varies from $4 \%$ to $23 \%$ and is usually associated with chronic renal disease, advanced age and more severe symptoms ${ }^{9,11}$.

Many studies have associated anemia to adverse clinical events in patients with $\mathrm{HF}^{2,8,12,13}$. Sales et a/2 observed $16.8 \%$ mortality in patients with anemia versus $8 \%$ in patients without anemia. Anand et a ${ }^{12}$ found $28 \%$ and $16 \%$ mortality in anemic and non-anemic patients, respectively, with hospitalization rates of $56 \%$ and $33 \%$, during a mean followup period of 12 months. The authors observed that each $01 \mathrm{~g} /$ $\mathrm{dL}$ of higher serum hemoglobin is associated with a reduction of $15.8 \%$ and $14.2 \%$ in risk of death and hospitalization, respectively. This influence does not depend on the type of HF according to the systolic function (preserved vs. deteriorated $)^{13,14}$. However, the link between anemia, HF and events is not clear, because anemia may only be a marker of increasing severity of HF or merely yet another comorbidity, giving patients a poor prognosis ${ }^{15}$.

Only $26 \%$ of patients evaluated had normal renal function, the majority (44\%) presented mild RI with GFR between 60 and $90 \mathrm{ml} / \mathrm{min}$ and nearly $30 \%$ had moderate-to-severe $\mathrm{RI}$. Chronic RI is a common comorbidity in HF patients,

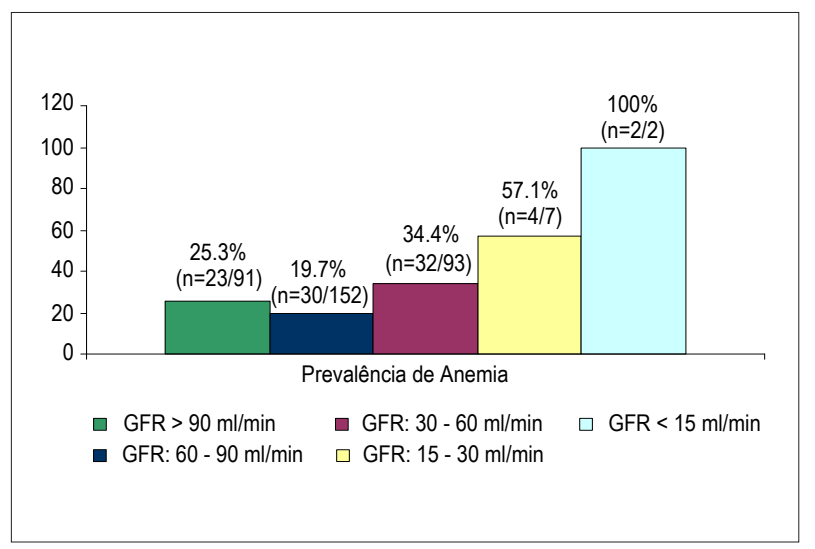

Chart 2 - Prevalence of anemia in patients grouped according to estimated glomerular filtration rate (GRF) calculated by the simplified Modification of Diet in Renal Disease (MDRD) equation $(n=345)$.

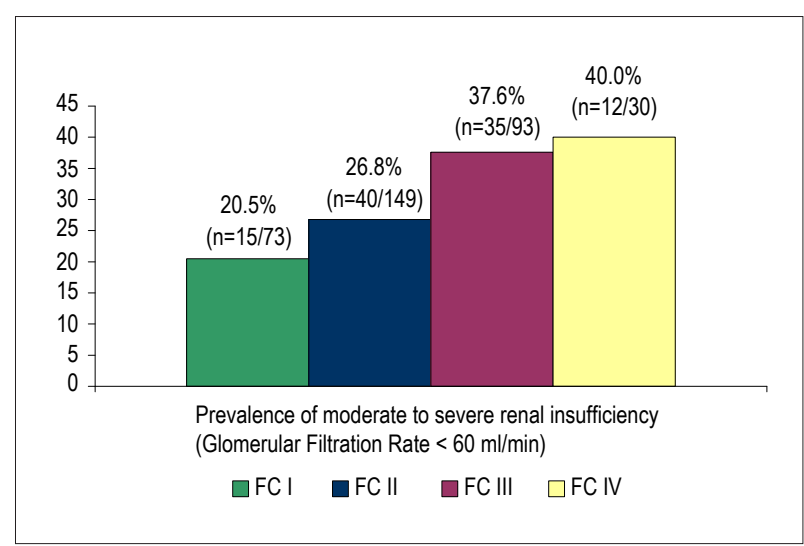

Chart 4 - Prevalence of moderate-to-severe renal insufficiency (Glomerular Filtration Rate $<60 \mathrm{ml} / \mathrm{min}$ ) in patients grouped according to New York Heart Association (NYHA) functional class (FC). 


\section{Original Article}

\section{Table 2 - Clinical characteristics of patients with and without anemia.}

\begin{tabular}{|c|c|c|c|}
\hline Characteristics & $\begin{array}{l}\text { Without anemia } \\
\qquad \mathrm{N}=254\end{array}$ & $\begin{array}{l}\text { With anemia } \\
\quad \mathrm{N}=91\end{array}$ & $\mathbf{P}$ \\
\hline Female gender - $\%$ & 41.3 & 50.5 & 0.140 \\
\hline Age in years: Mean (Standard Deviation) & $56.7(13.5)$ & $53.6(13.1)$ & 0.060 \\
\hline Negro race - \% & 41.7 & 45.1 & 0.622 \\
\hline Duration of heart disease: Median (P25-P75) & $36(21-84)$ & $48(15-96)$ & 0.980 \\
\hline Hypertension- \% (N) & 54.8 & 52.7 & 0.243 \\
\hline Diabetes Mellitus - \% (N) & 9.4 & 8.8 & 0.853 \\
\hline LVEF in \%: Median (P25-P75) & $36.2(27.5-45.0)$ & $36.0(28.5-47.0)$ & 0.841 \\
\hline Preserved Systolic Function (LVEF $\geq 45 \%$ ) - $\%$ & 28.3 & 29.7 & 0.893 \\
\hline NYHA Functional Class (FC) III or IV - \% & 29.5 & 52.7 & 0.000 \\
\hline Moderate-to-severe renal insufficiency (Glomerular Filtration Rate $<60 \mathrm{ml} / \mathrm{min}$ ) - \% & 25.2 & 41.8 & 0.005 \\
\hline \multicolumn{4}{|l|}{ Heart Failure Etiology - \% (N) } \\
\hline Chagasic & 44.1 & 42.9 & 0.902 \\
\hline Hypertensive & 22.0 & 18.7 & 0.552 \\
\hline Idiopathic & 12.2 & 9.9 & 0.703 \\
\hline Ischemic & 9.8 & 9.9 & 1.000 \\
\hline
\end{tabular}

LVEF - Left Ventricular Ejection Fraction / NYHA - New York Heart Association

Table 3 - Clinical characteristics of patients with and without moderate-to-severe renal insufficiency (Glomerular Filtration Rate - GFR $<60 \mathrm{ml} / \mathrm{min}$ )

\begin{tabular}{|c|c|c|c|}
\hline Characteristics & $\begin{array}{c}\text { GFR } \geq 60 \mathrm{ml} / \mathrm{min} \\
\mathrm{N}=243\end{array}$ & $\begin{array}{c}\mathrm{GFR}<60 \mathrm{ml} / \mathrm{min} \\
\mathrm{N}=102\end{array}$ & $\mathbf{P}$ \\
\hline Female gender - \% & 37.4 & 58.8 & 0.000 \\
\hline Age in years: Mean (Standard Deviation) & $51.3(12.5)$ & $62.0(12.1)$ & 0.000 \\
\hline Negro race - \% & 49.8 & 25.5 & 0.000 \\
\hline Duration of heart disease: Median (P25-P75) & $36(18-84)$ & $48(24-96)$ & 0.190 \\
\hline Hypertension- \% (N) & 53.3 & 56.4 & 0.248 \\
\hline Diabetes Mellitus - \% (N) & 9.1 & 9.8 & 0.840 \\
\hline LVEF in \%: Median (P25-P75) & $36.0(28.0-45.0)$ & $36.1(27.5-45.9)$ & 0.944 \\
\hline Preserved Systolic Function (LVEF $\geq 45 \%$ ) - \% & 28.0 & 30.4 & 0.696 \\
\hline NYHA Functional Class (FC) III or IV - \% & 31.3 & 46.1 & 0.010 \\
\hline Anemia - \% & 21.8 & 37.3 & 0.005 \\
\hline \multicolumn{4}{|l|}{ Heart Failure Etiology - \% (N) } \\
\hline Chagasic & 42.0 & 48.0 & 0.342 \\
\hline Hypertensive & 18.1 & 28.4 & 0.043 \\
\hline Idiopathic & 14.0 & 5.9 & 0.041 \\
\hline Ischemic & 10.7 & 7.8 & 0.553 \\
\hline
\end{tabular}

LVEF - Left Ventricular Ejection Fraction / NYHA - New York Heart Association 
it is associated with the disease severity, poorer prognosis and higher prevalence of anemia. Almost $40 \%$ of patients with HF have RI and more than $64 \%$ of those who go to nephrologists with kidney failure have HF, most of them with anemia ${ }^{10,16}$. Heart disease is a major problem in chronic kidney failure patients, being the cause of death in $43.6 \%$ of cases $^{17}$. For $\mathrm{O}^{\prime}$ Meara et $\mathrm{a} /{ }^{13}$, more than $50 \%$ of patients with $\mathrm{HF}$ and anemia have GFR below $60 \mathrm{ml} / \mathrm{min}$ compared to only $30 \%$ of those without anemia. Research shows that RI is an independent risk factor of mortality and hospitalization in patients with $\mathrm{HF}^{3}$.

Renal function must be accurately assessed using equations that estimate GFR from serum creatinine. International guidelines suggest the use of two formulas: Cockcroft-Gault or the simplified MDRD equation? ${ }^{7}$. The use of serum creatinine as an isolated parameter to evaluate renal function is not recommended due to its low sensitivity in the early stages of RI. In this study, whenever serum creatinine values were considered alone, using the cut-off point of $1.3 \mathrm{mg} / \mathrm{dL}$, only $18.3 \%$ of this population presented RI. Direct measurement of GFR through creatinine clearance would be the ideal method, although it is not superior to estimated GFR due to frequent errors in the 24-hour urine collection and daily variations in creatinine secretion, which is why this method is not routinely used.

The association of HF, anemia and CRS is responsible for faster progression of cardiac and renal diseases. Currently, mechanisms that lead to anemia in patients with HF are being studied to find treatments that can correct this complication and improve prognosis of these patients. Malnutrition, malabsorption and chronic gastrointestinal bleeding are common causes of anemia in HF patients, accounting for about $1 / 3$ of the cases $^{18}$. Excluding these situations, the mechanism involved in the development of anemia is generally related to deficient erythropoietin production ${ }^{19}$. Reduced hemoglobin concentration, in these cases, can also be caused by hemodilution resulting from the activation of the renin-angiotensin-aldosterone system (RAAS), which worsens prognosis ${ }^{20,21}$.

Erythropoietin produced by renal cells is the main regulator of red blood cells formation and deficient production is the main cause of anemia associated with isolated RI or in patients with concomitant $\mathrm{HF}$ and $\mathrm{RI}^{18}$. Causes of this disturbance include inflammatory cytokines, which can alter expression of the erythropoietin gene. In addition to interfering in erythropoietin production, cytokines have an important impact on iron metabolism, reducing its availability for erythropoiesis. Therefore, anemia in patients with CRS can be explained mainly by hypervolemia and hemodilution and by changes in the pathways of erythropoiesis, either in production or effect of erythropoietin or changes in iron metabolism, both caused by the presence of proinflammatory cytokines.

Studies in literature have evaluated the impact of anemia correction on the prognosis of patients with HF. Some authors have suggested that treatment with erythropoietin analogues and intravenous iron can improve LVEF, FC and $\mathrm{RI}$ in patients with HF and anemia, as well as decrease hospitalization rates and improve quality of life $\mathrm{e}^{10,22-25}$.
Published studies, however, are limited by sample size, and there is no consensus regarding the need for aggressive treatment of anemia in HF patients, especially in those with mild anemia and without $\mathrm{RI}^{15}$. In patients with moderateto-severe anemia and concomitant RI, treatment with erythropoietin and iron supplements is recommended to keep $\mathrm{Hb}$ greater than $12.0 \mathrm{~g} / \mathrm{dL}^{9}$. It is important that all patients be evaluated for potentially reversible causes of anemia, such as iron deficiency and occult blood loss, and receive adequate treatment. Silverberg et al. showed that anemia is still poorly investigated, recognized, and treated by cardiologists in the follow-up of non-hospitalized HF patients. These authors advocate cooperation between cardiologists and nephrologists to improve this data ${ }^{26}$.

The results of the present study must be considered within the context of certain limitations. At the time of data collection during visits of patients, other associated conditions that could possibly alter the levels of $\mathrm{Hb}$ and creatinine, such as sickle cell anemia, malnutrition, intestinal parasitic infections or obstructive uropathy, were not considered. We did find, however, a frequency of anemia and RI similar to previous data found in other populations. Our population is different from that of previous studies due to the high prevalence of Chagas disease as the main etiology of HF. Hypertension and ischemic disease, which are generally reported in literature as major etiologies of HF in other populations, are associated to higher risk of developing $\mathrm{RI}$ regardless of the presence of HF, which is not observed in Chagas Disease. Therefore, although we might expect a lower frequency of this complication in Chagas patients, this was not observed. We did not find a different prevalence of anemia or RI in patients with HF caused by Chagas Disease compared to other etiologies. Nevertheless, this study is of vital importance as it highlights the relevance of investigating the presence of these conditions in non-hospitalized HF patients, since the majority of published studies were carried out with hospitalized patients.

\section{Conclusion}

The results of this study demonstrated the high prevalence of anemia and RI in our population, similar to those found in international literature. Patients with these conditions were more decompensated (NYHA FC III and IV). Further prospective studies specifically evaluating anemia and renal function in patients with HF are needed to provide greater knowledge on these factors and their importance in HF severity and prognosis.

\section{Potential Conflict of Interest}

No potential conflict of interest relevant to this article was reported.

\section{Sources of Funding}

There were no external funding sources for this study.

\section{Study Association}

This study is not associated with any graduation program. 


\section{References}

1. Swedberg K, Cleland J, Dargie H, Drexler H, Follath F, Komajda M, et al. Guidelines for the diagnosis and treatment of chronic heart failure: executive summary (update 2005): The Task Force for the Diagnosis and Treatment of Chronic Heart Failure of the European Society of Cardiology. Eur Heart J. 2005; 26: 1115-40.

2. Sales ALF, Villacorta H, Reis L, Mesquita ET. Anemia as a prognostic factor in a population hospitalized due to decompensated heart failure. Arq Bras Cardiol. 2005; 84: 237-40.

3. Hillege HL, Nitsch D, Pfeffer MA, Swedberg K, McMurray JJ, Yusuf S, et al. Renal function as a predictor of outcome in a broad spectrum of patients with heart failure. Circulation. 2006; 113: 671-8.

4. Silverberg DS, Wexler D, Blum M, Wollman Y, Iaina A. The cardio-renal syndrome: does it exist? Nephrol Dial Transplant. 2003; 18 (Suppl.8): viii7viii 12 .

5. Gil P, Justo S, Caramelo C. Cardio-renal failure: an emerging clinical entity. Nephrol Dial Transplant. 2005; 20: 1780-3.

6. Silverberg D. Outcomes of anaemia management in renal insufficiency and cardiac disease. Nephrol Dial Transplant. 2003; 18 (Suppl 2): ii7-ii12.

7. National Kidney Foundation. K/DOQI clinical practice guidelines for chronic kidney disease: evaluation, classification, and stratification. Am J Kidney Dis. 2002; 39 (2 Suppl 1): S1-266.

8. Lindenfeld J. Prevalence of anemia and effects on mortality in patients with heart failure. Am Heart J. 2005; 149: 391-401.

9. Tang Y, Katz SD. Anemia in chronic heart failure: prevalence, etiology, clinical correlates, and treatment options. Circulation. 2006; 113: 245461.

10. Silverberg DS, Wexler D, Blum M, Keren G, Sheps D, Leibovitch E, et al. The use of subcutaneous erythropoietin and intravenous iron for the treatment of the anemia of severe, resistant congestive heart failure improves cardiac and renal function and functional cardiac class, and markedly reduces hospitalizations. J Am Coll Cardiol. 2000; 35: 1737-44.

11. Tanner H, Moschovitis G, Kuster GM, Hullin R, Pfiffner D, Hess OM, et al. The prevalence of anemia in chronic heart failure. Int J Cardiol. 2002; 86: 115-21.

12. Anand I, McMurray JJV, Whitmore J, Warren M, Pham A, McCamish MA, et al. Anemia and its relationship to clinical outcome in heart failure. Circulation. 2004; 110: 149-54.

13. O'Meara E, Clayton T, McEntegart MB, McMurray JJ, Lang CC, Roger SD, et al. Clinical correlates and consequences of anemia in a broad spectrum of patients with heart failure: results of the Candesartan in Heart Failure: Assessment of Reduction in Mortality and Morbidity (CHARM) Program. Circulation. 2006; 113: 986-94.
14. Latado AL, Passos LC, Darze ES, Lopes AA. Comparison of the effect of anemia on in-hospital mortality in patients with versus without preserved left ventricular ejection fraction. Am J Cardiol. 2006; 98: 1631-4.

15. Felker GM, Adams KF Jr, Gattis WA, O'Connor CM. Anemia as a risk factor and therapeutic target in heart failure. J Am Coll Cardiol. 2004; 44: 959-66.

16. Silverberg DS, Wexler D, Blum M, Schwartz D, Wollman Y, laina A. Erythropoietin should be part of congestive heart failure management. Kidney Int. 2003; 87 (Suppl): S40-7.

17. Bongartz LG, Cramer MJ, Doevendans PA, Joles JA, Braam B. The severe cardiorenal syndrome: 'Guyton revisited'. Eur Heart J. 2005; 26: 11-7.

18. de Silva R, Rigby AS, Witte KK, Nikitin NP, Tin L, Goode K, et al. Anemia, renal dysfunction, and their interaction in patients with chronic heart failure. Am J Cardiol. 2006; 98: 391-8.

19. Opasich C, Cazzola M, Scelsi L, De Feo S, Bosimini E, Lagioia R, et al. Blunted erythropoietin production and defective iron supply for erythropoiesis as major causes of anaemia in patients with chronic heart failure. Eur Heart J. 2005; 26: 2232-7.

20. Androne AS, Katz SD, Lund L, LaManca J, Hudaihed A, Hryniewicz K, et al. Hemodilution is common in patients with advanced heart failure. Circulation. 2003; 107: 226-9.

21. Westenbrink BD, Visser FW, Voors AA, Smilde TD, Lipsic E, Navis G, et al. Anaemia in chronic heart failure is not only related to impaired renal perfusion and blunted erythropoietin production, but to fluid retention as well. Eur Heart J. $2007 ; 28: 166-71$

22. Silverberg DS, Wexler D, Sheps D, Blum M, Keren G, Baruch R, et al. The effect of correction of mild anemia in severe, resistant congestive heart failure using subcutaneous erythropoietin and intravenous iron: a randomized controlled study. J Am Coll Cardiol. 2001; 37: 1775-80.

23. Mancini DM, Katz SD, Lamanca J, Hudaihed A, Androne AS. Effect of erythropoietin on exercise capacity in patientswith moderate to severe chronic heart failure. Circulation. 2003; 107: 294-9.

24. Bolger AP, Bartlett FR, Penston HS, O'Leary J, Pollock N, Kaprielian R, et al. Intravenous iron alone for the treatment of anemia in patients with chronic heart failure. J Am Coll Cardiol. 2006; 48 (6): 1225-7.

25. Silverberg DS, Wexler D, Blum M, Tchebiner IZ, Sheps D, Keren G, et al. The effect of correction of anaemia in diabetics and non-diabetics with severe resistant congestive heart failure and chronic renal failure by subcutaneous erythropoietin and intravenous iron. Nephrol Dial Transplant. 2003; 18 (1): 141-6.

26. Silverberg DS, Wexler D, laina A, Steinbruch S, Wollman Y, Schwartz D. Anemia, chronic renal disease and congestive heart failure - the cardio renal anemia syndrome: the need for cooperation between cardiologists and nephrologists. Int Urol Nephrol. 2006; 38: 295-310. 